\title{
Examining the Effect of Tablets to Enhance Essay Writing Competencies of Primary School Students
}

\author{
Tshewang Lhendup ${ }^{1}$, Ugyen Jimba ${ }^{2}$ \\ ${ }^{1}$ Sisina Primary School, Ministry of Education; Thimphu, Bhutan \\ ${ }^{2}$ Bjemina Primary School, Ministry of Education; Thimphu, Bhutan. \\ Received: 03 Sep 2021; Received in revised form: 27 Sep 2021; Accepted: 05 Oct 2021 \\ (C2021 The Author(s). Published by TheShillonga. This is an open access article under the CC BY license \\ (https://creativecommons.org/licenses/by/4.0/)
}

\begin{abstract}
Writing is one of the most important aspects of any standardized test all over the world. Much emphasis is hence placed on improving writing standards in schools and other forms of educational institutions. With improved technological infrastructure, digital devices such as Tablets are increasingly being used in the teaching and learning process.
\end{abstract}

This study aimed to explore the effects of Tablets in supporting grade VI students to enhance narrative essay writing skills. This particular study utilised 14 sessions comprising of 50 minutes each in both control and experimental situations. The control group is a simulation of a face-to-face teaching scenario, while the students in the experimental group replicated the non-contact teaching set-up. A total of 49 grade VI students from two primary schools selected using a convenience sampling technique participated in the study. The data for the study was collected through written tests both before and after the intervention. The analyses were conducted using descriptive statistics and $t$-tests.

The results showed that the differences in writing scores between control and experimental groups were statistically significant. Based on this finding, the use of Tablets in teaching essay writing may be considered helpful for primary schools irrespective of the school location.

Keywords-Bhutan, Essay writing, Primary school, Tablets.

\section{INTRODUCTION}

Students and teachers' digitisation of education and promoting the use of technology in the Bhutanese classrooms remain the top priority for the successive twelfth-year plans of the Royal Government of Bhutan (Ministry of Education [MoE], 2019). The need to develop digital competencies both for teachers and students are fast becoming a growing requirement. Technological skills are considered by many as an essential component of 21 stcentury learning and pedagogy to succeed in the rapidly evolving technology-driven society (OECD, 2015; U.S. Department of Education, 2017). Still, providing adequate computer-related resources and teacher training remains a challenge in most countries, particularly developing countries. The Royal Government of Bhutan's digital Bhutan flagship programme is committed to improving the technological resources in more than 609 schools spread across Bhutan with 1,70,000 students Policy and Planning Division (2020). As per the plan, by the end of the 2021 academic session, all grade $\mathrm{K}-10$ is to receive a Tablet each with support from Save the Children, country office (MoE,
2020). The dependence on e-learning as an alternative source of disseminating quality education has sharply increased in recent times (Onyema, 2020; OECD, 2020; Huber \& Helm, 2020).

Digital device accessibility is a significant problem, mostly in developing countries. The COVID-19 pandemic triggered the closure of schools in Bhutan and many other countries worldwide. As a consequence, numerous challenges were posed to both teachers and students alike during the online learning environment in Bhutan (MoE, 2021). For instance, many teachers and students had difficulties in conducting and attending online classes. Among the challenges, the digital divide challenges were often most prominent in rural schools and developing countries (Bergdahl \& Nouri, 2020; Iivari et al., 2020; OECD, 2020). Therefore, there is a need for students of rural schools to experience the authentic feel of learning using digital devices and prepare them to adequately have hands of experience to use the digital devices in their actual classroom learning. Responding to 21st-century learners' needs has been said and is much written about technology's 
relevance in the teaching and learning process (Choeda et al., 2016; Gautam et al., 2021).

Studies done on writing essays using Tablets in L1 settings are many, yet such studies are predominant in developed countries (Alkhouli, 2018). Currently, there is only one study in Bhutan that used i-pads as a complementing tool to teach essay writing conducted by Dhendup (2021). However, the scope of his study was targeted towards secondary students. Therefore, such a gap that exists explains that this is an area that should be researched to gain deeper insights and understanding with primary school children. The main contribution of this study is towards understanding the effect of Tablets in enhancing writing essays from a comparative perspective of two types of school. Such a study is the first of its kind and therefore hopes to contribute to scholarship in English as a foreign language context.

This current study aims to explore the effects of Tablets and teacher-led teaching approaches in improving student essay writing competencies in a rural and a semiurban primary school. A rural school in Bhutan's context refers to a place where basic infrastructure is still developing, while a semi-urban refers to a location having better facilities. The objectives of this study are to examine if there were statistical differences in essay writing scores between two groups of students. Therefore, this paper compares the differences in essay writing scores of participants in two groups. The findings of this study are expected to be of value and use to Language teachers, particularly to those teaching in English as a foreign and second language context.

This study is also expected to provide primary school students with the required 21 st-century experience of using digital devices as a learning tool to learn essay writing in the context of English as a foreign language. Further, our study contributes to scholarship related to the use of information systems in primary schools, specifically in developing country contexts. Additionally, for local teachers and students, it acts as a precursor to a learning management system (LMS), which is due to be introduced soon in Bhutanese schools. LMS can be defined as 'A selfcontained webpage with embedded instructional tools that permit faculty to organise academic content and engage students in their learning' (Gautreau, 2011, p.2). Besides, the use of digital technology is expected to provide children develop higher-order skills such as problem-solving, critical thinking, communication and collaboration (Roussinos \& Jimoyiannis, 2019; Morchid, 2020). Thus, the following research questions and null hypotheses are considered for investigation:
1. Is there a statistical difference in pre-test essay writing scores in the control and experimental group?

$\mathrm{H}_{0}$ 1: There is no statistical difference in pre-test essay writing scores in the control and experimental group.

2. Is there a statistical difference in post-test essay writing scores in the control and experimental group?

$\mathrm{H}_{0}$ 2: There is no statistical difference in post-test essay writing scores in the control and experimental group.

3. Is there a statistical difference between the pre and post-test writing scores of students after the intervention?

$\mathrm{H}_{0} 3$ : There is no statistical difference between the pre and post-test writing scores after the intervention.

\section{LITERATURE REVIEW}

Research related to technology use, particularly in the education sector, is not new; it has been widely studied in different cultural and educational settings (Raza et al., 2021). Many studies have been conducted on language learning using digital technologies, particularly mobile devices such as Tablets in both first (L1) and second language (L2) classrooms. The literature surrounding the use of technology in the classroom mainly indicate a positive and significant effect on children's academic achievement (Morchid, 2020; Estarki \& Bazyar, 2016). including children with learning disabilities Burke and Hughes (2017). They found out that iPads are being used in a constructive way across participants and countries, at all grade levels, and with students who have a range of special needs for a variety of learning purposes such as social, academic, communication, and functional.

For instance, in Sweden, a study by Alkhouli (2018) found that the use of mobile devices and their apps (online or offline) resulted in positive effects on learning English as a foreign language. Her study explored the newcomer's attitude towards language learning through mobile devices. The findings of her study revealed that there were significant positive degrees among newcomers in terms of efficiency, effectiveness and satisfaction toward mobile devices usability in the language classes.

Similarly, other researchers have also examined the advantages and the benefits of using digital devices in language learning classrooms, both in L1 and L2 classrooms (Kukulska-Hulme, 2013; Joshi \& Shah, 2015; 
Morchid, 2020). They pointed out through their studies that using mobile phones were said to have promoted interactivity, collaboration and active engagement in various learning activities of language learning. These studies reflect the importance of incorporating digital technology in language learning classrooms. Equally, Hazaea and Alzubi (2018, p. 55), in their investigation on the role of mobile technology in enhancing Learner Autonomy (LA) in Saudi Arabia, revealed that the participants (LA) "Improved through the use of selected mobile applications in terms of taking responsibility for and making decisions about reading materials and the time and place of reading."

While in Bhutan's case, a similar study was carried out by Dhendup (2021). Their study applied a mixedmethods study to examine the differences in secondary students writing performance using i-pads. The findings revealed that there was a significant improvement in posttest essay writing scores after the intervention. A statistically significant increase in the mean by more than 20 per cent was found. Therefore, his research substantiates that the use of mobile devices and Tablets promotes language learning, mainly showing significant improvements in writing skills. The study also proves that the use of digital devices by students while in classrooms is likely to influence positive learning and student achievement (Alkhouli, 2018), as evidenced by improvement in the post-test scores in both groups.

Further, Morchid's (2020), a relatively recent study, investigated the suitability of digital devices in the classrooms, Morchid suggested that digital devices offered opportunities for learners to further research into selflearning journey, thus promoting life-long learning. Likewise, a quantitative study carried out by Ali et al. (2019) indicated that Pakistani students had shown a positive predisposition towards mobile devices usage inside the language classrooms. Additionally, their study found out that the use of digital devices not only supported learning with ease and comfort but also motivated learners to learn in a collaborative learning environment.

Estarki and Bazyar's (2016) study aimed at finding the effect of using mobile-assisted language learning on the writing performance of pre-intermediate Iranian learners' using Viber applications was similar to that reported by Malekzadeh and Najmi (2015) study. Their study explored the effect of mobile-assisted language learning on guided writing of Iranian upper-intermediate using text messages. The results of their study showed that there was a difference in the performance of the experimental and the control groups, where participants in the experimental group performed better in post-test compared to participants in the control group. These researchers found a noticeable improvement in student writing quality, whose research was also carried out in the L2 context.

Hence, our study is an attempt to shed some light on the two-teaching approach. This present study situates and is relevant in the context of teaching and learning English as a foreign language in a developing country.

\section{METHODOLOGY}

\subsection{Target Participants}

The target participants of this study are all students of two schools. A convenience sampling method was used to select the participants. The first school is a rural school where $(\mathrm{N}=27)$ with 14 students assigned in experimental and 13 in the control group. The second school was categorised as semi-urban where $(\mathrm{N}=22)$, where 11 students each were placed in the control and experiment group respectively. However, for the purpose of data computation and analyses, the participant's scores from both these schools in both pre and post-tests were put together in their respective group, experimental $(n=25)$ and control group $(n=24)$.

\subsection{Intervention Procedure}

This particular study utilised 14 sessions comprising of 50 minutes each in both control and experimental situations in both the school types. The fivewriting process adopted for this study was prewriting, drafting, revising, proofreading and publishing and was based on the new English curriculum. The control group replicated a non-contact teaching situation where the teacher-led the intervention programme. While for the treatment group, one Lenovo Tab M8 (TB-8505F) each was provided to the individual student. The tablet contained downloaded materials based on the new normal curriculum, for instance, explanation on effective writing (central idea, organisation, supporting materials, expression, word choice, point of view, Spelling, Grammar, and punctuation) mostly in video format. The related materials on effective writing were also provided in the control group, where one English teacher led the teaching simulating a face-to-face set-up, which was mainly teacher-centred. The ethical clearance for this study was granted by the respective school Research Committee (SRC).

Prior to intervention, a pre-test on narrative essay writing was administered to all the participants individually based on the primary curriculum, which essentially follows the competency-based assessment test (CBAT) format (see appendix 1). The question format were similar to Bhutan Council of School Examination (BCSEA), who annually prepares the questions for grade VI students nationwide, 
while the evaluation of these test papers was carried out by teachers of the participating school (BCSEA, 2019).

After the session on intervention, the measure was over, a post-test was conducted with all the students and tested individually. The children were given (30 minutes) to complete the essay writing task, which was again based on the new normal curriculum. The level and the pattern of questions were similar to the pre-test. Children in grade Six are required to write a narrative essay of about 200 words (Royal Education Council, 2021). The completed essay writing scripts were assessed on both occasions (pre and post).

\subsubsection{Scoring Procedure}

The essay writing task was assessed by 3 English teachers in both schools. The test takers were scored based on five broad criteria following the standards of the national curriculum, for instance, (Sentence structure, Grammar and spelling, capitalisation and punctuation, closing paragraph and Introduction); (see Appendix 2 for assessment criteria). The highest score under each evaluation criteria was four, and no points were awarded for incorrect answers. The total number of marks awarded was 20 . The interrater scores are expressed in terms of simple percentages. The final interrater average scores were considered for data analyses and interpretation.

\subsection{Data collection and Data Analysis}

This study employed a quantitative design and followed a convenience sampling technique to select the participants. The data were collected through pre-test and post-test essay writings administered individually. The two tests were conducted to examine the differences in writing scores. Both pre and post-tests required children to write a narrative essay based on the three options of questions for about 30 minutes. The total marks were 20, which is similar to the BCSEA question pattern in primary English. The quantitative data for this study were computed using the SPSS conventions (version 23) and MS excel 2019.

To test for data normality, Shapiro Wilk's test method of normality is applied based on the recommendation of Allen et al. (2014), the sample for this current study is $<50$. Additionally, the data set was further inspected for potential outliers using the boxplot. Then a series of independent samples t-test and a paired samples ttest non-parametric equivalent was performed to compare the pair of groups. The alpha to determine statistical test significance was set at 0.05 .

\section{RESULTS}

$H_{0}$ 1: There is no statistical difference in pre-test essay writing scores in the control and experimental group.

$H_{0}$ 2: There is no statistical difference in post-test essay writing scores in the control and experimental group.

To answer $\mathrm{H}_{0} 1$ and $\mathrm{H}_{0} 2$, a descriptive statistic and two sets of independent samples t-test were applied. An independent samples t-test was computed firstly for the pretest and then subsequently for the post-test. Independent ttests were conducted to determine if a difference exists between the means of two groups. The data is hence expressed as mean and standard deviation (Mean \pm Standard Deviation). There were 24 participants in the control group and 25 in the experimental group. It can be seen from Table 1 that the mean score of pre-test between the control and experimental group was marginal $(8.02 \pm 3.08 ; 7.86 \pm 2.22)$.

Table 1: Group statistics for gender, group and tests.

\begin{tabular}{llcccccc}
\hline & & \multicolumn{3}{c}{ Pre-test } & \multicolumn{3}{c}{ Post-Test } \\
\cline { 3 - 8 } & & M & SD & N & M & SD & N \\
\hline \multirow{3}{*}{ School_T } & Rural & 1 & 8 & 7 & 3 & 6 & 7 \\
\cline { 2 - 8 } ype & Semi- & 7.2 & 2.8 & 2 & 10. & 2.8 & 2 \\
& Urban & 2 & 2 & 2 & 2 & 8 & 2 \\
\hline \multirow{3}{*}{ Group_ty } & Control & 2 & 6 & 4 & 35 & 2 & 4 \\
\cline { 2 - 8 } pe & Experime & 7.8 & 2.2 & 2 & 11. & 2.2 & 2 \\
& ntal & 6 & 2 & 5 & 01 & 5 & 5 \\
\hline \multirow{3}{*}{ Gender } & Male & 7.1 & & 1 & 9.5 & 2.4 & 1 \\
& & 5 & 2.3 & 9 & 7 & 4 & 9 \\
\cline { 2 - 8 } & & 8.4 & 2.7 & 3 & 11. & 2.5 & 3 \\
& Female & 3 & 7 & 0 & 5 & 5 & 0 \\
\hline
\end{tabular}

Prior to pre-test result analysis, a normality test was assessed to examine the normality of the data. A Shapiro-Wilk for the dependent variable pre-writing test score for the control and experiment group was conducted. The Shapiro-Wilk test is generally considered suitable for smaller samples (Allen et al., 2014, p.38). The ShapiroWilk in control group was $(w=0.932)$ and $($ Sig $=0.108)$, and similarly for experimental group $(w=0.943$ and $S i g=$ 0.174 ) wherein both the cases, the dependent variable, pretest writing scores in Table 2 is non-significant ( $p>0.05$ ). Also, there was homogeneity of variances, as assessed by Levene's test for equality of variances $(p=0.835)$. The mean difference of $0.160(95 \% \mathrm{CI},-1.38$ to 1.70$), t(47)=$ $0.210, p=0.835$ is not significant. 
Likewise, for the post-test, the Shapiro-Wilk in control group was $(w=0.975)$ and $($ Sig $=0.778)$, and alike for experimental group ( $w=0.954$ and $\operatorname{Sig}=0.302)$ wherein both the cases, the post-test score considered as a dependent variable (see Table 3) was non-significant ( $>0.05)$. Similarly, the homogeneity of variances, as assessed by Levene's test for equality of variances $(p=0.307)$.
Therefore, the normality assumption is considered normal for the present study. The non-significant difference of 0.760 (95\% CI, -2.31 to 0.744$), \mathrm{t}(47)=-1.0, p=0.307$ was recorded for post-test scores between the two groups. Hence, in both (pre-test and post-test), the differences in mean scores are the same in the control and experimental group is accepted.

Table 2: Test of normality for pre-test

\begin{tabular}{llcccccc}
\hline & & \multicolumn{3}{c}{ Kolmogorov-Smirnov $^{\mathrm{a}}$} & \multicolumn{3}{c}{ Shapiro-Wilk } \\
\cline { 2 - 8 } & Group Type & Statistic & df & Sig. & Statistic & df & Sig. \\
\hline Pre-test & control & .168 & 24 & .078 & .932 & 24 & .108 \\
& Experimental & .140 & 25 & $.200 *$ & .943 & 25 & .174
\end{tabular}

*. This is a lower bound of the true significance.

a. Lilliefors Significance Correction

Table 3: Test of normality for post-test

\begin{tabular}{llcccccc}
\hline & & \multicolumn{3}{c}{ Kolmogorov-Smirnov $^{\mathrm{a}}$} & \multicolumn{3}{c}{ Shapiro-Wilk } \\
\cline { 3 - 7 } & Group_type & Statistic & $\mathrm{df}$ & Sig. & Statistic & $\mathrm{df}$ & Sig. \\
\hline Post-test & control & .105 & 24 & $.200^{*}$ & .975 & 24 & .778 \\
& Experimental & .155 & 25 & .123 & .954 & 25 & .302 \\
\hline
\end{tabular}

*. This is a lower bound of the true significance.

a. Lilliefors Significance Correction

Table 4: Results of independent samples t-test by Group type

\begin{tabular}{|c|c|c|c|c|c|c|c|c|}
\hline \multirow[b]{3}{*}{$\begin{array}{l}\text { Pre- } \\
\text { test }\end{array}$} & \multirow[b]{3}{*}{$\begin{array}{l}\text { Equal variances } \\
\text { assumed }\end{array}$} & \multicolumn{2}{|c|}{$\begin{array}{l}\text { Levene's Test } \\
\text { for Equality of } \\
\text { Variances }\end{array}$} & \multicolumn{5}{|c|}{ t-test for Equality of Means } \\
\hline & & $\mathrm{F}$ & Sig. & $\mathrm{t}$ & $\mathrm{df}$ & \multirow{2}{*}{$\begin{array}{c}\text { Sig. (2- } \\
\text { tailed) } \\
.835\end{array}$} & \multirow{2}{*}{$\begin{array}{c}\text { Mean } \\
\text { Difference }\end{array}$} & \multirow{2}{*}{$\begin{array}{c}\text { Std. Error } \\
\text { Difference } \\
.766\end{array}$} \\
\hline & & 2.701 & .107 & .210 & 47 & & & \\
\hline & $\begin{array}{l}\text { Equal variances not } \\
\text { assumed }\end{array}$ & & & .208 & 41.7 & .836 & .160 & .771 \\
\hline \multirow[t]{2}{*}{$\begin{array}{l}\text { Post- } \\
\text { test }\end{array}$} & $\begin{array}{l}\text { Equal variances } \\
\text { assumed }\end{array}$ & 2.55 & .116 & -1.0 & 47 & .307 & -.785 & .760 \\
\hline & $\begin{array}{l}\text { Equal variances not } \\
\text { assumed }\end{array}$ & & & -1.0 & 42.5 & .310 & -.785 & .765 \\
\hline
\end{tabular}

$H_{0}$ 2: There is no statistical difference between the pre and post-test writing scores of students after the intervention

A descriptive analysis of pre and post-test scores is presented in Table 4 between the two groups. The data is expressed as being Mean \pm Standard Deviation. It can be seen from Table 4 that for pre-test $(7.93 \pm 2.65)$ and for the post-test $(10.75 \pm 2.66)$. The results show that the participants in the post-test had done better compared to the pre-test score. The minimum essay writing score in the pretest was 3.50 , while the maximum was 14.50 . Similarly, the 
maximum and minimum scores after the intervention had increased in this case.

Table 4: A descriptive statistic between pre and post-test

\begin{tabular}{lccccc}
\hline & $\mathrm{N}$ & Mean & $\begin{array}{l}\text { Std. } \\
\text { Deviation }\end{array}$ & Minimum & Maximum \\
\cline { 2 - 6 } $\begin{array}{l}\text { Pre- } \\
\text { test }\end{array}$ & 49 & 7.93 & 2.65 & 3.50 & 14.50 \\
$\begin{array}{l}\text { post- } \\
\text { test }\end{array}$ & 49 & 10.75 & 2.66 & 5.00 & 16.00 \\
\hline
\end{tabular}

Further, in order to test the hypothesis that there is no difference between the pre and the post-test writing scores, a possibility to run the repeated measures t-test was explored. However, two outliers, for instance, case numbers 37 and 47, were detected after the difference between the pair pre and post-test were computed. The outliers exhibited more than 1.5 box lengths from the edge of the box in a boxplot. Also, the test of normality using Shapiro Wilk's test on difference statistics was $(w=0.909)$ and $(\mathrm{Sig}=$ 0.077 , where $\mathrm{p}=0.001$ was lesser than the accepted alpha value of $>0.05$. The significant value of $(p<0.05)$ evidenced that a repeated measures t-test could not be run in this case (see Table 5). However, upon the inspection, their values were revealed not to be extreme, and they were retained for the analysis. Hence, a non-parametric equivalent of paired t-test, a Wilcoxon signed-rank test, was administered. This test is applied as the outliers were retained for the analyses. Forty-nine participants were recruited to the study in order to determine the effect of the intervention, namely teacher-led and the use of Tablets. The data is then expressed in medians. Of the forty-nine participants recruited to the study, the post-test score increase is seen in 46 participants compared to the pre-test score, while two participants' scores in post-test decreased, and one participant's score remained unchanged (see Table 6 ). A Wilcoxon signed-ranked test showed that there was evidence of a statistically significant median increase in post-test score after the intervention was carried out in both the groups (2.5 marks) (see Table 7). The median scores and the test statistics of the Wilcoxon Signed Ranks test is presented in Table 7 and Table 8, respectively. The median in post-test was (11) and compared to (8) in pre-test, the $z=$ $-5.920, p<0.05$.

Table 5: Test of normality for the difference in score

\begin{tabular}{lllcccc}
\hline & \multicolumn{3}{c}{ Kolmogorov-Smirnov $^{\mathrm{a}}$} & \multicolumn{4}{c}{ Shapiro-Wilk } \\
\cline { 2 - 7 } & Statistic & df & Sig. & Statistic & df & Sig. \\
\hline difference & .120 & 49 & .077 & .909 & 49 & .001 \\
\hline
\end{tabular}

a. Lilliefors Significance Correction

Table 6: Ranks of post and pre-test

\begin{tabular}{llccc}
\hline & & N & Mean Rank & Sum of Ranks \\
\hline post-test - Pretest & Negative Ranks & $2^{\mathrm{a}}$ & 6.00 & 12.00 \\
& Positive Ranks & $46^{\mathrm{b}}$ & 25.30 & 1164.00 \\
& Ties & $1^{\mathrm{c}}$ & & \\
& Total & 49 & & \\
\hline
\end{tabular}
a. posttest < Pretest
b. posttest > Pretest
c. posttest $=$ Pretest

Table 7: Median of pre and post-test with a difference

\begin{tabular}{ccc}
\hline Pre-test & post-test & difference \\
\hline 8.0000 & 11.0000 & 2.5000 \\
\hline
\end{tabular}

Table 8: Test statistics of Wilcoxon Signed Ranks Test

\begin{tabular}{lc}
\hline & post-test - Pretest \\
\hline $\mathrm{Z}$ & $-5.920^{\mathrm{b}}$ \\
Asymp. Sig. (2-tailed) & .000
\end{tabular}




\section{DISCUSSION AND CONCLUSION}

This present study attempted to examine the effect of Tablets and the teacher-led approaches to enhance essay writing competencies of two Bhutanese primary school students. The main aim of this study was to see if there were differences in essay writing scores after the intervention had been given. The results of the Wilcoxon signed-rank test showed a significant mean difference. Evidence of a statistically significant median increase in post-test scores in both the groups ( 2.5 marks) shows that in both the teaching contexts, there was a significant change in the posttest scores. While there are many factors in the change of result in the teacher-led context, one possible reason that could have accounted for a significant increase may be due to a smaller number of students. For instance, 11 students in school A (semi-urban) was placed in the control group, while only 13 students were placed in the control group in school B (rural). The increase in post-test writing scores, in this case, is due to the small class size as compared to 3040 students in normal teaching situations. At the same time, the improved writing performance in the experimental group could be attributed to participants' own personal interest and the sheer motivation they showed to digital gadgets in learning. It may be partly due to learnerautonomy granted to these children during the sessions as teachers were able to guide and facilitate learning. This finding is similar to the findings of Dhendup (2021), where statistically significant results in post-test writing scores of secondary students were observed. Although the differences in post-test scores between the group type were not statistically significant, nonetheless $(0.7)$, which is close to a $3.5 \%$ increase, was found. Therefore, this finding of the study somewhat suggests that the use of Tablets could be beneficial to assist primary school children to write better essays as the post-test score in the experimental group was (11.01) while the control post-test score was (10.35).

This research also tested the hypothesis that there is no statistical difference in pre-test scores between in terms of control and experimental group. The result of the independent samples t-test showed there was no statistically significant difference when the pre-test score was taken as a dependent variable. Similarly, the post-test scores between the two groups did not yield a statistically significant result. Therefore, the finding in this respect is inconsistent with the previous study of (Malekzadeh \& Najmi, 2015), where they observed statistically significant differences in post-test results, a study carried out with Iranian secondary schools.

However, the mean difference between the pre and post-test in both control and experimental group, although not significant with a mean difference of (3.15 marks) in post-test scores seem to support the idea that the use of Tablets may play a crucial role in further advancing and transacting better classroom learning and teaching processes.

Finally, the statistically significant median difference between the pre and post-test in both the teaching contexts indicates that the use of Tablets can be helpful in providing writing support to students. The study also found that the post-test scores in the teacher-led (control) group saw improved scores. The improved difference may be actualised only if there is smaller class size.

\subsection{Implications}

This study has few practical implications for Language teachers in the context of English as a Foreign language teaching. The use of Tablets should be explored in helping students acquire writing skills. The increased posttest scores, particularly in the experimental group, support our claim in its relevance and usability. Further, it has been observed that participants in the experimental group did not show any signs of learning fatigue as opposed to teacher-led sessions in both schools. Similarly, participants were found to be taking responsibility for their own learning in their respective teams, thus promoting collaboration and learning autonomy.

The study findings also have implications for policymakers, and there is an immediate need to upgrade and strengthen internet connectivity in rural areas. It has been found that without stable internet connections, there are far-reaching negative implications for accessing online learning materials prescribed in the new curriculum fully. Chances for digital inequality, if unsolved, will create digital divisions within the geographical types.

\subsection{Limitation and Future Direction.}

This present study had its own limitations. The first limitation was the accuracy of data as it was collected from two different schools. This may have impacted the study's findings as different English teachers were involved in the evaluation of the writing tests. Although English teachers were involved in the carrying out the intervention and the conduct of tests, however, due to varied teacher qualifications and teaching experience, there may have been instances of variations in scoring the tests. Another limitation of this study was the lack of resources such as Tablets and unstable internet connectivity. Participants in the experimental group could not be supplied with individual Tablets, which meant that sharing Tablets with peers would have led to discomfort, limiting the interaction time, hence affecting their post-test performance. In both schools, internet accessibility posed a severe problem. 
Therefore, the related materials were only confined to offline downloaded materials. Lastly, since the study was purely quantitative, the results of this may not be helpful in understanding in-depth trends and patterns associated with the study findings.

Therefore, to gain accurate information, future studies may deploy a mixed-methods study design. The use of interviews and class observations would be helpful in this case. Further studies may also explore the use of Tablets in other subjects like Sciences and Mathematics.

\section{ACKNOWLEDGEMENT}

The authors would like to thank Mr Sonam Dhendup of Yangchen Gatshel MSS, Thimphu, for assisting us with the final editing and reviewing of this manuscript. Also, this study would not have been possible without the assistance of English teachers and students of Bjemina and Sisina Primary school. Finally, we offer our appreciation to Mr Tashi Namgyel and Mrs Lham Tshering, District Education officers, Thimphu, for their unstinted support and encouragement.

\section{REFERENCES}

[1] Allen, P., Bennett, K., \& Heritage, B. (2014). SPSS Statistics Version 22: A practical guide. Cengage Learning.

[2] Alkhouli, S. (2018). Usability of mobile-assisted language learning: Swedish language learning for newcomers in Sweden. International Journal of Business and Management; Canadian Center of Science and Education, 13(11).

[3] Ali, M. M., Mahmood, M.A., \& Anwar, M.N. (2019). Pakistani learners' perceptions regarding mobile assisted language learning in ESL classroom. International Journal of English Linguistics, 9(4).

[4] Bergdahl, N., \& Nouri, J. (2020). Covid-19 and CrisisPromted Distance Education in Sweden.Technology, Knowledge and Learning, 1-17. https://doi.org/10.1007/s10758-020- 09470-6

[5] Bhutan Council for School Examinations and Assessment (2019). Year-end Assessment Report 2019; GRADE VI CBAT 2018. Assessment and Monitoring Division.

[6] Burke, A., \& Hughes, J. (2018). A shifting landscape: Using tablets to support learning in students with diverse abilities. Technology, Pedagogy and Education, 27(2), 183198. https://doi.org/10.1080/1475939X.2017.1396492

[7] Choeda, Penjor, T., Dupka, D., \& Zander, P. (2016). The state of Integration of the Virtual Learning Environment and ICT into the pedagogy of the Royal University of Bhutan: A descriptive study. International Journal of Education and Development using Information and Communication Technology, 12(1), 71-88.

[8] Dhendup, S. (2021). Effects of Digital Media Devices on English Essay Writing Competencies among Rural
Secondary School Students in Bhutan. i-manager's Journal on School Educational Technology, 16(3), 1524. https://doi.org/10.26634/jsch.16.3.17522

[9] Gautam, K. P., Sharma, D., Wangpo, K., \& Dema, S. (2021). The Acceptance and Use of the Virtual Learning Environment (VLE) in Higher Education: A Contextual Study of Royal University of Bhutan. Asian Research Journal of Arts \& Social Sciences, 13(3), 20-36. https://doi.org/10.9734/arjass/2021/v13i330215

[10] Gautreau, C. (2011). Motivational factors affecting the integration of a learning management system by faculty. Journal of Educators Online, 8(1), 1-25. https://www.learntechlib.org/p/52833/

[11] Estarki, N.K., \& Bazyar, M. (2016). The effect of mall on pre-intermediate EFL learners' writing performance. European Online Journal of Natural and Social Sciences, 5(2), 406-420.

[12] Hazaea, A. N., \& Alzubi, A. A. (2016). The Effectiveness of Using Mobile on EFL Learners' Reading Practices in Najran University. English language teaching, 9(5), 8-21.

[13] Huber, S. G., \& Helm, C. (2020). COVID-19 and schooling: evaluation, assessment and accountability in times of crises - reacting quickly to explore critical issues for policy, practice and research with the school barometer. Educational Assessment, Evaluation and Accountability, 134. https://doi.org/10.1007/s11092-020-09322-y

[14] Iivari, N., Sharma, S., \& Ventä-Olkkonen, L. (2020). Digital transformation of everyday life-How COVID-19 pandemic transformed the basic education of the young generation and why information management research should care? International Journal of Information Management, 102183. https://doi.org/10.1016/j.ijinfomgt.2020.102183

[15] Kukulska-Hulme, A. (2013). Re-skilling language learners for a mobile world. Monterey, CA: The International Research Foundation for English Language Education. http://www.tirfonline.org/english-in-the-workforce/mobileassisted-language- learning/

[16] Malekzadeh, R., \& Najmi, K. (2015). The effect of mobileassisted language learning (MALL) on guided writing skill of Iranian upper-intermediate EFL learners. Journal of Applied Linguistics and Language Research, 2(4), 42-52.

[17] Morchid, N. (2020). Mobile-Assisted Language Learning: Evidence of an Emerging Paradigm. International Journal of English Literature and Social Sciences (IJELS), 5(1).

[18] Ministry of Education. (2020). COVID-19 response plan: Guidelines for Curriculum Implementation Plan for Education in Emergency (EiE). Ministry of Education.

[19] Ministry of Education. (2019). iSherig-2: Education ICT master plan 2019-2023. Ministry of Education. http://www.education.gov.bt/wp-content/uploads/2019/ 05/iSherig-2- Education-ICT-MNasterplan-2019-2023.pdf

[20] Ministry of Education (2021). Education in Emergencies (EiE) Druring Covid -19 Report. Education Monitoring Division.

[21] OECD. (2015). Students, computers and learning: Making the connection. OECD Publishing. https://doi.org/ 10.1787/9789264239555-en. 
[22] OECD (2020). School Education During COVID-19: Were Teachers and Students Ready? OECD Publishing.

[23] Onyema, E. M., Eucheria, N. C., Obafemi, F. A., Sen, S., Atonye, F. G., Sharma, A., \& Alsayed, A. O. (2020). Impact of Coronavirus Pandemic on Education. Journal of Education and Practice.11(13). 108 - 121.

[24] Policy and Planning Division (2020). Annual education statistics. Ministry of Education.

[25] Roussinos, D. \& Jimoyiannis, A. (2019): Examining Primary Education Teachers' Perceptions of TPACK and the Related Educational Context Factors, Journal of Research on Technology in Education. https://doi.org/10.1080/15391523.2019.1666323

Appendix 1
[26] Raza, S.A., Qazi, W., Khan, K.A. and Salam, J. (2021). Social Isolation and Acceptance of the Learning Management System (LMS) in the time of COVID-19 Pandemic: An Expansion of the UTAUT Model. Journal of Educational Computing Research, https:// 10.1177/0735633120960421.

[27] Royal Education Council (2021). Instructional guide for English Class VI. Royal Education Council.

[28] U.S. Department of Education. (2017). Reimagining the role of technology in education: 2017 National Education Technology Plan update. Office of Educational Technology.

\section{SECTION A: Writing}

\section{Question I - 20 Marks}

Direction: Write a narrative essay of about 200 words on any $\mathrm{ONE}$ of the topics given below.

1. The summer vacation has been extended to a month long duration since 2017. Write about how you have spent your summer vacation in 2018.

2. Imagine that you got an opportunity to meet one of your favourite actors for about an hour. Narrate about how you met him or her, what you did and how you felt about the meeting.

3. Complete the story beginning with, "Jigme, with a cup of tea in his hand, looked at his brother Dorji sitting across the table. Jigme said, "We are here to celebrate..."

https://www.bcsea.bt/questions-download

\section{Appendix 2}

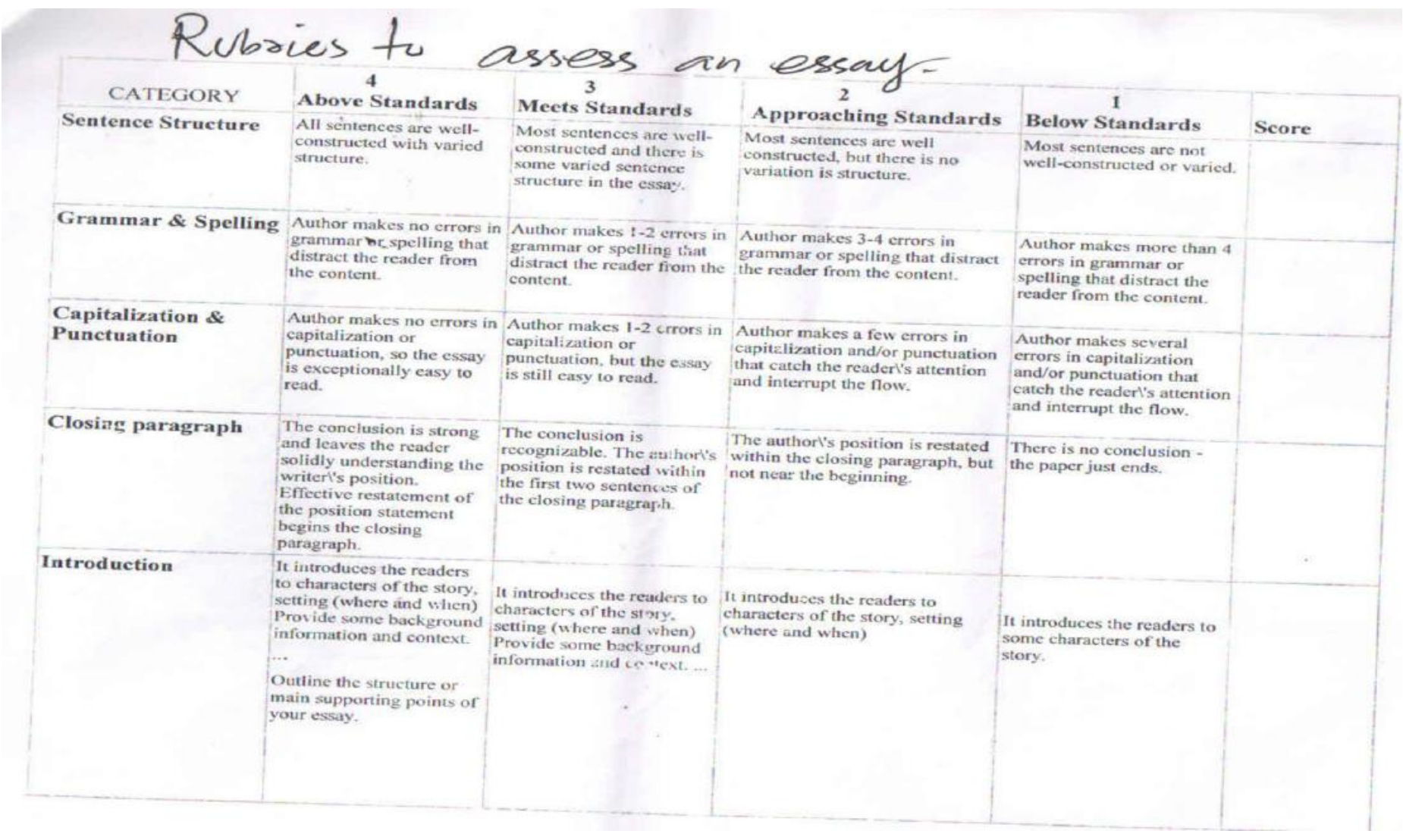

